\title{
Load-dependent surface diffusion model for analyzing the kinetics of protein adsorption onto mesoporous materials
}

Gregorio Marbán*, Luis A. Ramírez-Montoya, Héctor García, J. Ángel Menéndez, Ana Arenillas and Miguel A. Montes-Morán

Instituto Nacional del Carbón (INCAR-CSIC) - c/Francisco Pintado Fe 26, 33011-Oviedo (Spain). Tel. +34 985119090; Fax +34985297662

\begin{abstract}
The adsorption of cytochrome $\mathrm{c}$ in water onto organic and carbon xerogels with narrow pore size distributions has been studied by carrying out transient and equilibrium batch adsorption experiments. It was found that equilibrium adsorption exhibits a quasi-Langmuirian behavior (a $\mathrm{g}$ coefficient in the Redlich-Peterson isotherms of over 0.95) involving the formation of a monolayer of cyt $\mathrm{c}$ with a depth of $\sim 4 \mathrm{~nm}$ on the surface of all xerogels for a packing density of the protein inside the pores of $0.29 \mathrm{~g} \mathrm{~cm}^{-3}$. A load-dependent surface diffusion model (LDSDM) has been developed and numerically solved to fit the experimental kinetic adsorption curves. The results of the LDSDM show better fittings than the standard homogeneous surface diffusion model. The value of the external mass transfer coefficient obtained by numerical optimization confirms that the process is controlled by the intraparticle surface diffusion of cyt $\mathrm{c}$. The surface diffusion coefficients decrease with increasing protein load down to zero for the maximum possible load. The decrease is steeper in the case of the xerogels with the smallest average pore diameter $(\sim 15 \mathrm{~nm})$, the limit at which the zero-load diffusion coefficient of cyt $\mathrm{c}$ also begins to be negatively affected by interactions with the opposite wall of the pore.
\end{abstract}

Keywords: Adsorption, kinetics, surface diffusion, protein, mesoporous

‘ Corresponding author: greca@incar.csic.es 


\section{Introduction}

Adsorption by porous solids in liquid phase is a process of paramount importance in the fields of water treatment, liquid-phase separation, chromatography, etc. The modelling of liquid-phase adsorption is usually performed using well-known adsorption kinetic models [1], which allow the experimental data to be fitted in a relatively simple manner although, in many cases, they lack the theoretical basis necessary for comparing different adsorption systems. Many of the models employed are merely phenomenological, based on simple pseudo-empirical equations, and can be divided into adsorption reaction models, in which the rate determining step is the adsorption stage (i.e., pseudo-first order rate models based on the Lagergren model [2], pseudo-second order rate models [3], the second order rate model [4], and Elovich's equation [5, 6]), and adsorption diffusion models, in which the kinetic process of adsorption is controlled either by liquid film diffusion [7] or by intraparticle diffusion [8-10]. Theoretical adsorption models are more complex and difficult to use in practice for fitting experimental results because the differential equations that comprise the main body of the models yield very complex and restricted analytical solutions or must be solved by means of numerical procedures. However, by applying numerical solving routines made possible by computers, realistic adsorption models, that provide a better interpretation and comparison of the fitted parameters, can be constructed so that the complicated procedure is reduced to a simple matter of personal choice.

There are a number of theoretical adsorption reaction models [11-18], based on the Langmuir [19, 20] or BET [21] isotherms, (in the case study of the BET kinetic model, a simple analytical solution has only recently been found [22]), as well as theoretical adsorption diffusion models, based on Fick's second law. The adsorption diffusion models [23-29] are differentiated by the possible combinations of the three diffusion steps that govern the overall process: (i) liquid film diffusion, (ii) pore diffusion and (iii) surface diffusion. An adsorption system in which adsorption diffusion is known to be the rate determining step is one which involves the recovery, purification or 
immobilization of proteins through ion-exchange, adsorption chromatography or porous-particle adsorption [30-32]. This process has usually been described by using four types of adsorption diffusion models: (i) the pore diffusion model, where the driving force for intraparticle mass transfer is the protein concentration gradient in the pore phase, with no surface diffusion [28, 31], (ii) the surface diffusion model, in which surface diffusion is the rate-limiting step in the adsorption process [33], (iii) the homogeneous diffusion model, which considers each adsorbent particle as a homogeneous network, and the driving force for protein diffusion is the total protein concentration gradient within the adsorbent $[34,35]$ and (iv) the parallel diffusion model, which assumes that pore and surface diffusion occur at the same time in an adsorbent particle [36, 37]. In a work by Chen $e t$ al. [38] the four models were solved by an orthogonal collocation method, under the assumption that external liquid-film mass transfer resistance was negligible and then used to fit the experimental curves of the adsorption kinetics of bovine serum albumin (BSA) and $\gamma$-globulin to an anion exchanger. They found that the parallel diffusion model provided the best fit for the experimental data.

An important feature of standard pore and surface diffusion models which is often ignored is that the diffusion coefficients are always independent of the spatial coordinates. This simplifies enormously the task of numerically resolving the mass balances. Thus, in the classical homogeneous surface diffusion model by Mathews, Weber and Walter [24-26] that employs spherical coordinates, in the intraparticle mass balance expressed by equation (1), the surface diffusion coefficient is always treated as a constant and equation (1) can be transformed into the more easily solvable equation (2);

$\frac{\partial q(r, t)}{\partial t}=\frac{1}{r^{2}} \frac{\partial}{\partial r}\left(r^{2} D_{S} \frac{\partial q(r, t)}{\partial r}\right)$

$\frac{\partial q(r, t)}{\partial t}=D_{S}\left(\frac{2}{r} \frac{\partial q(r, t)}{\partial r}+\frac{\partial^{2} q(r, t)}{\partial r^{2}}\right)$

where $\mathrm{q}(\mathrm{r}, \mathrm{t})$ is the amount of adsorbate adsorbed onto the surface of the porous particle $\left(\mathrm{mg} \mathrm{g}^{-1}\right)$ at the radial position $\mathrm{r}(\mathrm{cm})$ and at time $\mathrm{t}(\mathrm{s})$ and $\mathrm{D}_{\mathrm{S}}\left(\mathrm{cm}^{2} \mathrm{~s}^{-1}\right)$ is the surface diffusion coefficient or 
surface diffusivity. However, to assume that surface diffusivity is independent of the radial coordinate is a disputable point [39]. According to the HIO theory of Higashi et al. [40], which is based on the random displacement of molecules between adsorption sites on a solid surface, the transition time between sites is negligible when compared to the residence time on each site, and the molecule jumps across immediately when it encounters a site already occupied by another molecule. From this theory, Kapoor and Yang [39] derived the following expression for the spatial-dependent surface diffusivity:

$D_{S}(r, t)=\frac{D_{0}}{1-\theta(r, t)}$

where $\mathrm{D}_{0}$ is the diffusion coefficient at zero coverage and $\theta(\mathrm{r}, \mathrm{t})$ is fractional surface coverage, $\mathrm{q}(\mathrm{r}, \mathrm{t}) / \mathrm{q}_{\mathrm{m}}, \mathrm{q}_{\mathrm{m}}$ being the maximum amount of adsorbate loaded by the particle in $\mathrm{mg} / \mathrm{g}$. Later it was proved that equation (3) was a specific case covered by the general model for surface diffusion of gases in porous solids formulated by Chen and Yang [41, 42], this particular case corresponding to the absence of blockage in the channel opening. This model predicts an initial increase in the diffusion coefficient up to coverages close to a monolayer and its subsequent decrease due to multilayer condensation. Other authors take into consideration the affinity between adsorbed molecules. For instance, Zhdanov [43] suggests the use of the following empirical equation:

$D_{S}(r, t)=D_{0} \times e^{\alpha \times \vartheta(r, t)}$

where parameter $\alpha$ is positive for repulsive and negative for attractive lateral interactions between adsorbed particles. Whereas equation (3) has been proved to be valid for gases at low degrees of coverage, whether bulky proteins behave similarly when adsorbed on a solid surface is open to dispute. For instance, Tilton et al. [33] found a significant hindrance of surface diffusion that increases with increasing surface concentration, owing to interactions between the adsorbed proteins. In that case parameter $\alpha$ of equation (4) should present a negative value. However, no kinetic model 
for the adsorption (either of proteins or of any other adsorbate) onto porous solids that considers the dependence of the diffusion coefficient on the surface coverage has ever been fully solved.

In the present work we propose and solve a load-dependent surface diffusion model for protein adsorption that follows Fick's second law in which (a) surface diffusivity depends on surface coverage (load) via a new empirical relation and (b) external liquid-film mass transfer resistance is considered. The model has been tested in the adsorption of cytochrome $\mathrm{c}$ onto mesoporous organic and carbon xerogel particles synthesized by means of microwave heating [44-46].

\section{Load-dependent surface diffusion model (LDSDM)}

This model is a variation of the homogeneous surface diffusion model (HSDM) initially proposed by Mathews, Weber and Walter [24-26] and later simplified by the Linear driving force approximation [27]. The HSDM assumes that the surface of adsorbent particles is homogeneous and that the adsorbate is transferred from one adsorption site to an inner adsorption site inside the particles, according to Fick's second law [25]. In the HSDM, the diffusion coefficient is considered to be independent of the amount of adsorbate in the sorbent (load) at any time, whereas the present model (LDSDM) considers that the surface diffusion coefficient varies with the load according to the following equation:

$D_{S}(r, t)=D_{0}+\left(D_{m}-D_{0}\right) \times\left(\frac{q(r, t)}{q_{m}}\right)^{m}$

where $\mathrm{D}_{\mathrm{S}}\left(\mathrm{cm}^{2} \mathrm{~s}^{-1}\right)$ is the load-dependent surface diffusion coefficient, $\mathrm{D}_{0}\left(\mathrm{~cm}^{2} \mathrm{~s}^{-1}\right)$ is the surface diffusion coefficient at zero load $(\mathrm{q}=0)$ and $\mathrm{D}_{\mathrm{m}}\left(\mathrm{cm}^{2} \mathrm{~s}^{-1}\right)$ is the surface diffusion coefficient at maximum load $\left(q=q_{m}\right)$. This equation predicts an increasing $D_{S}$ value with the load when $D_{m}>D_{0}$, a constant diffusivity coefficient (HSDM) when $\mathrm{D}_{\mathrm{m}}=\mathrm{D}_{0}$ and a decreasing $\mathrm{D}_{\mathrm{S}}$ value with the load when $D_{m}<D_{0}$. Assuming this load-dependent diffusion coefficient to be valid, equation (2) for homogeneous surface diffusion in spherical coordinates becomes: 
$\frac{\partial q(r, t)}{\partial t}+\psi(r, t)=D_{0}\left(\frac{2}{r} \frac{\partial q(r, t)}{\partial r}+\frac{\partial^{2} q(r, t)}{\partial r^{2}}\right)$

where

$\psi(r, t)=\frac{\partial q(r, t)}{\partial t}\left(\frac{D_{0}}{D_{S}(r, t)}-1\right)-\frac{m D_{0}\left(D_{S}(r, t)-D_{0}\right)}{D_{S}(r, t) q(r, t)}\left(\frac{\partial q(r, t)}{\partial r}\right)^{2}$

Thus, the load-dependent surface diffusion model, equation (6), reverts to the homogeneous surface diffusion model, equation (2), when the non-linear term $\psi(r, t)$ is equal to zero, that is, when $\mathrm{D}_{\mathrm{S}}(\mathrm{r}, \mathrm{t})=\mathrm{D}_{0}$.

The total adsorbate load within the particles at a time $\mathrm{t}\left(\overline{q(t)}, \mathrm{mg} \mathrm{g}^{-1}\right)$ is evaluated as:

$\overline{q(t)}=\frac{3}{R^{3}} \int_{0}^{R} r^{2} q(r, t) d r$

where $\mathrm{R}(\mathrm{cm})$ is the radius of the particle that is assumed to be spherical. The concentration of adsorbate in the liquid bulk at a time $\mathrm{t}\left(\mathrm{C}_{\mathrm{b}}(\mathrm{t}), \mathrm{mg} \mathrm{cm}^{-3}\right)$ can be evaluated as:

$C_{b}(t)=C_{0}-D_{A} \overline{q(t)}$

where $\mathrm{C}_{0}$ is the initial concentration of adsorbate in the liquid volume $\left(\mathrm{mg} \mathrm{cm}^{-3}\right)$ and $\mathrm{D}_{\mathrm{A}}$ is the adsorbent dosage $\left(\mathrm{g} \mathrm{cm}^{-3}\right)$. By taking the derivative of (7) with respect to $\mathrm{t}$ and substituting (1) into the resulting equation, the following expression for the adsorption rate is obtained [27]:

$\frac{\partial \overline{q(t)}}{\partial t}=\frac{3}{R} D_{S}(R, t) \frac{\partial q(R, t)}{\partial r}$

Also, the adsorption rate can be evaluated by considering the liquid-film mass transfer from the bulk to the external surface of the particles [26]:

$\frac{\partial \overline{q(t)}}{\partial t}=\frac{3 k_{s}}{R \rho_{a}}\left[C_{b}(t)-C_{s}(t)\right]$

where $\mathrm{k}_{\mathrm{S}}$ is the external mass transfer coefficient $\left(\mathrm{cm} \mathrm{s}^{-1}\right), \rho_{\mathrm{a}}$ is the apparent density of the sorbent particles $\left(\mathrm{g} \mathrm{cm}^{-3}\right)$ and $\mathrm{C}_{\mathrm{S}}(\mathrm{t})$ is the adsorbate concentration in the liquid at the surface of the particles ( $\mathrm{mg} \mathrm{cm}^{-3}$ ). By introducing (8) into (9) and equating (9) and (10), the following equation is obtained: 
$\frac{\partial q(R, t)}{\partial r}=\frac{k_{S}}{D_{S}(R, t) \rho_{a}}\left[C_{0}-D_{A} \overline{q(t)}-C_{s}(t)\right]$

which is one of the border equations at $\mathrm{r}=\mathrm{R}$. The other border equation at this radial position is obtained by assuming that the load at the external surface is in equilibrium with the adsorbate concentration in the liquid at the same position:

$q(R, t)=\frac{A C_{S}(t)}{1+B C_{S}(t)^{g}}$

This equation is the well-known Redlich-Peterson isotherm [47]. Parameters A, B and g must be previously evaluated from the equilibrium adsorption experiments to obtain the variation in the concentration of the adsorbate in the liquid at equilibrium $\left(\mathrm{C}_{\mathrm{e}}, \mathrm{mg} \mathrm{cm}^{-3}\right)$ as a function of the load at equilibrium $\left(\mathrm{q}_{\mathrm{e}}, \mathrm{mg} \mathrm{g}^{-1}\right)$ :

$q_{e}=\frac{A C_{e}}{1+B C_{e}^{g}}$

The other border equations of the LDSDM are:

$\frac{\partial q(0, t)}{\partial r}=0$

$q(r, 0)=0$

The model was numerically solved using a homemade Microsoft ${ }^{\circledR}$ Excel macro based on a finite difference method using the Crank-Nicolson's scheme. Equation (6) was discretized to obtain a tridiagonal system of equations in which the non-linear function $\psi(r, t)$ was incorporated into the independent terms. The number of radial intervals was optimized to 50 and the time increment to 200 s. The non-linear equations were solved in two nested loops: an internal loop for evaluating the $\mathrm{q}(\mathrm{r}, \mathrm{t})$ profile at given values of $\mathrm{t}$ and $\mathrm{C}_{\mathrm{S}}(\mathrm{t})$ using the Thomas algorithm for tridiagonal matrixes and an external loop to obtain the optimal $\mathrm{C}_{\mathrm{S}}(\mathrm{t})$ value via equation (11). In both loops, a NewtonRaphson optimization procedure was employed (to solve the linear HSDM equations $(\psi(\mathrm{r}, \mathrm{t})=0)$ no optimization was needed for the internal loop). The maximum load ( $\left.\mathrm{q}_{\mathrm{m}}\right)$ was taken to be the load at 
$\mathrm{C}_{\mathrm{e}}=0.6 \mathrm{mg} \mathrm{cm}^{-3}$. Finally, to optimize the values of the external mass transfer coefficient $\left(\mathrm{k}_{\mathrm{s}}\right)$ and the surface diffusivity parameters $\left(\mathrm{D}_{0}, \mathrm{D}_{\mathrm{m}}\right.$ and $\left.\mathrm{m}\right)$, a Simplex algorithm was used in order to minimize the sum of the quadratic differences between the experimental and calculated values of $\mathrm{C}_{b}(t)$ :

$$
\mathrm{E}=\sum\left[C_{b}(t)^{\exp }-C_{b}(t)^{c a l c}\right]^{2}
$$

With the coefficients thus obtained, the value of the mass transfer Biot number was evaluated as follows:

$B i_{m}=\frac{k_{S} R}{3 D_{S}}$

where $\mathrm{D}_{S}$ has been taken to be equal to $\mathrm{D}_{0}$ in the LDSDM. When this number is below 1 liquid-film mass transfer controls the adsorption process, whereas for values over $\sim 30$, internal surface diffusion is the rate determining step $[48,49]$.

\section{Experimental}

\section{Preparation of mesoporous xerogels}

Three different organic xerogels (OX-15, OX-30, OX-55) and the corresponding carbon xerogels (CX-15, CX-30, CX-55) were prepared for this study by using a method reported previously [44-46]. Essentially, the organic xerogels were first synthesized by means of the polycondensation of resorcinol (Indspec, 99.6\% purity) and formaldehyde (Merck, 37\% aqueous solution, including 0.7\% methanol) (RF) in deionized water and methanol (VWR Chemicals, Normapur $>99.9 \%$ purity) using selected conditions [46]. A lab-made microwave device was employed to heat the solutions up to $85^{\circ} \mathrm{C}$ over a period of $3 \mathrm{~h}$. The excess of water was afterwards reduced by continuing to heat the gel in the microwave oven until a mass loss of over $50 \%$ of the initial weight was achieved. Samples of the organic xerogels ( $25 \mathrm{~g}$ ) were converted into CXs by heating them in a quartz reactor (i.d. $30 \mathrm{~mm}$ ) placed in a horizontal electrical tube furnace (Carbolite Type MFT 12/38/400), under a nitrogen flow 
rate of $100 \mathrm{~cm}^{3} \mathrm{~min}^{-1}$ up to $700^{\circ} \mathrm{C}$ at $50^{\circ} \mathrm{C} \mathrm{min}^{-1}$ and $2 \mathrm{~h}$ dwelling time. The carbonized RF xerogel particles were cooled down to room temperature under the same nitrogen flow rate. Finally, both the organic and carbon xerogels were milled and sieved to obtain particles of $\sim 0.5 \mathrm{~mm}$ mean radius. The suffix in the sample labels $(-15,-30$ and -55$)$ indicate their average pore diameters in nanometers as determined from mercury porosimetry (see below) [46].

\section{Characterization}

$\mathrm{N}_{2}$ adsorption-desorption isotherms were obtained at $-196^{\circ} \mathrm{C}$ in a Micromeritics Tristar II volumetric adsorption system. Prior to measurement, the samples were outgassed by heating them overnight at $120^{\circ} \mathrm{C}$ under vacuum. The Brunauer-Emmett-Teller and Dubinin-Radushkevich models were selected to determine the BET surface area $\left(\mathrm{S}_{\mathrm{BET}}\right)$ and micropore volume $\left(\mathrm{V}_{\mu}\right)$ of the analyzed samples from the nitrogen adsorption data, respectively. The Pore Size Distributions (PSD) of selected samples were calculated from the $\mathrm{N}_{2}$ physisorption isotherms by means of the 2D-NLDFT model [50]. Their apparent density $\left(\rho_{\mathrm{a}}\right)$ was determined in mercury on a Micromeritics AutoPore IV apparatus. The samples were also outgassed at $120^{\circ} \mathrm{C}$ overnight. The mean pore diameter and total pore volume (for pore sizes $>3.5 \mathrm{~nm}$ ) of the CX samples were evaluated in a mercury porosimeter with a maximum operation pressure of $227 \mathrm{MPa}$. The OX samples subjected to the same analytical procedure yielded ambiguous results due to sample compressibility. All the pertinent textural data obtained from these characterization techniques are included in Table 1.

\section{Protein adsorption experiments}

Cytochrome c (cyt c) obtained from a bovine heart (Sigma-Aldrich, ref C2037) was selected for the immobilization experiments due to its high purity $(\geq 95 \% ; 12327 \mathrm{Da})$. Solutions of cyt c ( 0.5 and $0.8 \mathrm{mg} \mathrm{cm}^{-3}$ for kinetic experiments and between 0.1 and $1.0 \mathrm{mg} \mathrm{cm}^{-3}$ for the equilibrium adsorption 
experiments) were prepared in a buffer solution of sodium phosphate $(\mathrm{pH}=6)$. The total ionic strength was set to $100 \mathrm{mM}$. The OX and CX particles were suspended in the buffer solution $24 \mathrm{~h}$ prior to their use in the adsorption experiments. In both the kinetic and equilibrium tests, $10 \mathrm{mg}$ (7.5 mg in one specific test) of OX or CX was suspended in $5 \mathrm{~cm}^{3}$ of the cyt $\mathrm{c}$ solution prepared in the phosphate buffer. This operation was carried out in individual screw top vials for each point of the kinetic curves and the adsorption isotherms. The vials were orbitally shaken at 200 r.p.m. (75 r.p.m. in one specific test) and kept at $30^{\circ} \mathrm{C}$ in an incubator shaker (TH 15 model from Edmund Bühler $\mathrm{GmbH}$ ) for up to $96 \mathrm{~h}$ (time for the equilibrium adsorption) or for predetermined times (to obtain the adsorption kinetics data). After the pre-established adsorption times, the supernatant solution was used to quantify the cyt $\mathrm{c}$ content remaining in liquid phase. The concentration of cyt $\mathrm{c}$ in the solutions was determined by UV-vis spectrometry (Shimadzu UV-2401 PC scanning spectrophotometer). Absorbances at ca. $410 \mathrm{~nm}\left(\varepsilon=10^{5} \mathrm{M}^{-1} \mathrm{~cm}^{-1}\right)$ were used to determine the concentration of cyt $\mathrm{c}$ in a given solution. Each individual adsorption experiment was performed at least twice to ensure statistical soundness, with insignificant deviations in all cases. Average loads were used for the calculations and displays.

\section{Results and Discussion}

\section{Model simulations}

In order to confirm the soundness of the model, several simulations were performed prior to testing it with experimental adsorption kinetic curves. Two blocks of simulations were performed, the results of which are shown in Figures 1 and 2, respectively. In the first block (Fig. 1) the operation conditions were varied [particle size, agitation speed ( $\mathrm{Bi}_{\mathrm{m}}$ values), adsorbent dosage, initial adsorbate concentration and apparent density], whereas the second block of simulations (Fig. 2) was focused on variations in the surface diffusion coefficient parameters [equation (5)]. For the adsorption 
isotherm [equation (13)] the parameters corresponding to CX-30 were used in all the simulations (Table 1). The equilibrium cyt $\mathrm{c}$ adsorption isotherm for this material $\left(\mathrm{R}=0.05 \mathrm{~cm}, \rho_{\mathrm{a}}=0.46 \mathrm{~g} \mathrm{~cm}^{-3}\right)$ is shown in Figure 4 and will be extensively discussed in the following section. For the simulations displayed in Figure 1 a common surface diffusion coefficient that decreases linearly with the load [m=1 in equation (5)] was adopted (left inset in Figs. 1A to 1E). An increase in the particle size (Fig. 1A) caused a sharp decrease in the adsorption rate (and a corresponding increase in the adsorbate concentration, right inset in Fig. 1A), only due to the restricted diffusion of the adsorbate within the particle as the radius increased. The values of external mass transfer Biot numbers $\left(\mathrm{Bi}_{\mathrm{m}}\right)$ in this case range from $166.7(\mathrm{R}=0.05 \mathrm{~cm})$ to $666.7(\mathrm{R}=0.20 \mathrm{~cm})$ and, in view of the results shown in Figure 1B, no external mass transfer resistance can be expected for the simulations displayed in Fig. 1A. As can be seen in Figure 1B, only for values of $\mathrm{Bi}_{\mathrm{m}}$ below $\sim 80$ is there a noticeable decrease in the adsorption rate. It is also apparent that the adsorbent dosage does not affect the initial rate of adsorption; i.e., all curves in the lower plot of Figure 1C are coincident up to a stage close to equilibrium. In contrast, the total amount adsorbed does vary with $\mathrm{D}_{\mathrm{A}}$; it remains practically constant for $D_{A}<0.005 \mathrm{~g} \mathrm{~cm}^{-3}$ because the values of adsorbate concentration $\left(C_{b}\right)$, though clearly affected in that range by the adsorbent dosage (right inset in Fig. 1C), fall within the almost horizontal plateau of the adsorption isotherm (Fig. 4). For $D_{A}=0.005 \mathrm{~g} \mathrm{~cm}^{-3}$ the decrease in $\mathrm{C}_{\mathrm{b}}$ with time is so great that the total amount adsorbed is much smaller. A similar result is obtained by varying the initial adsorbate concentration (Figure 1D). For a fixed value of $\mathrm{D}_{\mathrm{A}}, \mathrm{C}_{0}$ mainly affects the equilibrium adsorbate concentration that correspondingly influences the amount adsorbed as reflected by the adsorption isotherm (Fig. 4). Therefore, only in the case of the lowest initial adsorbate concentration $\left(0.05 \mathrm{mg} \mathrm{cm}^{-3}\right)$ does the equilibrium adsorbate concentration fall within the zone of the adsorption isotherm before the plateau (Fig. 4). For this reason the total amount adsorbed appears to be significantly smaller than that obtained at higher $\mathrm{C}_{0}$ values (lower plot in Fig. 1D). The apparent density does not seem to have any effect on the adsorption kinetics, as can be seen in Figure 1E. The 
reason for this is purely mathematical since, from a physical point of view, a decrease in the apparent density of a given material would be indicative of a wider pore system and, potentially, a higher surface diffusion coefficient. Thus, any real variation in the apparent density would probably yield kinetic curves similar to those included in Figure 2A, which will be discussed below. The curves displayed in Fig. 1E therefore must correspond to materials with different densities though with the same type of pore system (i.e., the same surface diffusion coefficients).

Figure 2 shows the results of the simulations performed where the dependence of the surface diffusion coefficient on the load varies (left insets in Figs. 2A to 2D). The decrease in $\mathrm{D}_{0}$ for a surface diffusion coefficient that linearly $(m=1)$ decreases with the load down to zero provokes, as might be expected, a clear decrease in the adsorption rate (Figure 1A; lower plot and right inset). A similar trend is observed with the decrease in the parameter $\mathrm{m}$ (Figure 1B): the steeper the decrease in $\mathrm{D}_{\mathrm{S}}$, the slower the adsorption rate. Figure 1C highlights the difference between the homogeneous surface diffusion model ( $\mathrm{D}_{\mathrm{S}}$ independent of load) and the load-dependent surface diffusion model for linearly decreasing $\mathrm{D}_{\mathrm{S}}$ coefficients. The restricted diffusion of the adsorbate inside the particle with increasing load causes a corresponding decrease in the adsorption rate. Finally, for the hypothetical case of a linearly increasing surface diffusion coefficient with the load (left inset in Figure 2D) it can be seen that the value of the diffusion coefficient at zero load $\left(\mathrm{D}_{0}\right)$ hardly has any effect on the adsorption rate for a common value of $\mathrm{D}_{\mathrm{m}}$. Due to the low value of the surface diffusion coefficient, adsorption in this case takes place according to a shrinking core model in which the adsorbate diffuses through the layers immediately surrounding the core, which are heavily loaded from the very beginning of the process.

\section{Equilibrium results}


The robustness of the kinetic model proposed here was tested using experimental data obtained from the adsorption of proteins on organic (OXs) and carbon xerogels (CXs). These materials have been singled out as excellent candidates for studying the interaction of biomolecules with porous materials, specifically with the aim of determining the effect of pore size on their adsorption and activity [46]. The porous structure of RF xerogels has been extensively reported [44-46, 51]. The nanostructure of these materials is essentially composed of packed quasi-spherical nodules that can be observed by SEM and TEM [51, 52]. The voids between the spheres constitute the porosity of the materials. Accordingly, if the size of the nodules is narrowly controlled during the synthesis, the resulting pore size distribution must also be relatively narrow [44-46]. It is quite obvious, however, that, in spite of the narrow pore distributions, these materials cannot be considered ordered mesoporous solids [51].

Figures 3 and 4 show the equilibrium adsorption isotherms corresponding to the adsorption of cyt $c$ onto the OX and CX samples, respectively. The lines in the figures represent fittings to the RedlichPeterson isotherm, whose parameters A, B and g [equation (13)] are listed in Table 1 for the different samples. In most cases parameter $\mathrm{g}$ is close to 1 , as in the Langmuir isotherm, which suggests the formation of a cyt c monolayer on the internal surface of the samples. The CX-15 and CX-30 isotherms exhibit a point of intersection at $\mathrm{C}_{\mathrm{e}} \sim 0.17 \mathrm{mg} \mathrm{cm}^{-3}$, which is relevant in relation to our previous work [46], in which it was stated that CX-30 had a similar adsorption capacity to CX-15 at $\mathrm{pH}=6$ (Fig. 5 in [46]). The experiments in that study were carried out at $\mathrm{C}_{0}=0.5 \mathrm{mg} \mathrm{cm}^{-3}$ and $D_{A}=0.002 \mathrm{~g} \mathrm{~cm}^{-3}$, resulting in an equilibrium concentration, $C_{e}$, very close to the point of intersection of both isotherms (Fig. 4). Since the kinetic experiments reported in the present work were performed under the same conditions, the values of $\mathrm{q}_{\mathrm{e}}$ for $\mathrm{CX}-15$ and CX-30 shown in Table 1 are also very similar. On the other hand, the values of $\mathrm{q}_{\mathrm{m}}$ in Table 1, which represent approximately the maximum attainable load for each sorbent at $30^{\circ} \mathrm{C}\left(\mathrm{q}_{\mathrm{e}}\right.$ values calculated for $\mathrm{C}_{\mathrm{e}}=0.6 \mathrm{mg} \mathrm{cm}^{-3}$ in Figs. 3 and 4), prove that CX-15 $\left(\mathrm{q}_{\mathrm{m}}=202.4 \mathrm{mg} \mathrm{g}^{-1}\right)$ performs better than CX-30 $\left(\mathrm{q}_{\mathrm{m}}=167.3 \mathrm{mg} \mathrm{g}^{-1}\right)$. In 
[46], it was stated that the entire pore volume of CX-15 was occupied by cyt c, under the assumption of a packing density for this protein of $0.17 \mathrm{~g} \mathrm{~cm}^{-3}$, which corresponds to the density of a cyt $\mathrm{c}$ molecule (other sources indicate $0.14 \mathrm{~g} \mathrm{~cm}^{-3}$ [53]). In view of the new value of $\mathrm{q}_{\mathrm{m}}$ for $\mathrm{CX}-15$ and considering the pore volume of this material (Table 1), the packing density of cyt $\mathrm{c}$ must be at least $0.23 \mathrm{~g} \mathrm{~cm}^{-3}$ (corresponding to the complete pore volume filling of CX-15). External surface adsorption is very low in these materials (below $10 \mathrm{mg} \mathrm{g}^{-1}$ ) as evaluated for a CX-5 sample [46], and certainly too low for a packing density value below the aforementioned $0.23 \mathrm{~g} \mathrm{~cm}^{-3}$ to be considered. Besides, it is improbable that the entire pore volume of CX-15 would be filled by the cyt $\mathrm{c}$ protein considering that the CX-5 sample with a mean pore diameter of $5 \mathrm{~nm}$ hardly adsorbs any cyt c [46]. In view of the quasi-Langmuirian behavior of the materials and the probable cyt $\mathrm{c}$ monolayer depth ( $3-5 \mathrm{~nm}$, judging from the molecule dimensions [53-55]), a monolayer of this depth would reduce the mean pore size of CX-15 to a value similar to that of CX-5, which would be insufficient to permit any additional cyt $\mathrm{c}$ adsorption. The fraction of pore volume occupied by the adsorbate at equilibrium can be evaluated for the CX samples, on the basis of unambiguous mercury intrusion data, by means of the following equation:

$X_{V}=\frac{q_{m}}{1000 \rho_{p} V_{p}}$

where $\rho_{\mathrm{p}}$ is the packing density of the adsorbate $\left(\mathrm{g} \mathrm{cm}^{-3}\right)$ and $\mathrm{V}_{\mathrm{p}}$ is the volume of accessible pores $\left(\mathrm{cm}^{3} \mathrm{~g}^{-1}\right)$, as evaluated by mercury intrusion. Assuming Langmuirian behavior and cylindrical pores with a mean pore diameter $\left\langle\mathrm{d}_{\mathrm{p}}\right\rangle(\mathrm{nm})$, the depth (D) of the adsorbed layer $(\mathrm{nm})$ can be evaluated by means of the following expression:

$D=\frac{\left\langle d_{p}\right\rangle}{2}\left[1-\left(1-X_{V}\right)^{0.5}\right]$

By setting the packing density to a value of $\rho_{\mathrm{p}}=0.29 \mathrm{~g} \mathrm{~cm}^{-3}$ in equation (18), a consistent value for the adsorbed layer depth (D) of $\sim 4 \mathrm{~nm}(4.0 \pm 0.2 \mathrm{~nm})$ is obtained for all the CX samples, regardless of the mean pore diameter, with fractions of pore volume occupancy ranging from 0.27 for CX-55 to 
0.79 for CX-15 (Table 1). In summary, an imposed packing density value for cyt $\mathrm{c}$ of $0.29 \mathrm{~g} \mathrm{~cm}^{-3}$ and the quasi-Langmuirian behavior of the isotherms would allow the presence of a cyt $\mathrm{c}$ monolayer of $\mathrm{D} \sim 4 \mathrm{~nm}$ to be confirmed for all the CX samples. The high value of the cyt $\mathrm{c}$ packing density might be a consequence of factors such as the $\mathrm{pH}$ of the solution or its ionic strength [46].

A similar line of reasoning can be applied to the OX samples. First of all, the isotherm shape of the $\mathrm{OX}$ samples is also quasi-langmuirian $(\mathrm{g}>0.95)$, so that the presence of a cyt $\mathrm{c}$ monolayer at maximum load can be expected. Unfortunately, the pore size distributions observed in these samples with the mercury intrusion technique present bizarre shapes, unlike the neat distributions obtained for the CX samples (Fig. 2 in [46]), and therefore the values of mean pore diameter for OX cannot be evaluated with precision. Due to this, neither the values of $\mathrm{X}_{\mathrm{V}}$, nor those of $\mathrm{D}$ can be directly estimated for the OX samples. These samples are compressible at high pressures and, therefore, the mercury intrusion data are not completely reliable $[56,57]$. Nevertheless, the pore volumes obtained via $\mathrm{Hg}$ intrusion exhibit similar values to those of the $\mathrm{CX}$ samples as well as comparable $\mathrm{q}_{\mathrm{m}}$ values (Table 1). In addition, as exemplified below (Figure 8), the $\mathrm{N}_{2}$ adsorption isotherms of any given $\mathrm{CX}$ and OX pair are almost identical, though with higher adsorbed amounts in the case of CX due to the microporosity formed during the carbonization of OX. Hence, it can be reasonably assumed that the pore size distributions of OXs in the mesoporous region and larger pores would also be narrow and similar to those of their CX counterparts. The BET specific surface area values of OX are much lower than those of the CX samples, due to the larger microporosity of the latter (Table 1). However, as micropores do not contribute to protein adsorption, the maximum loads for the OX samples are, as mentioned above, similar to those of the corresponding CX samples ( $\mathrm{q}_{\mathrm{m}}$, Table 1). In this respect, the OX samples can be expected to exhibit $\mathrm{X}_{\mathrm{V}}$ values analogous to those of the $\mathrm{CX}$ samples.

\section{Adsorption kinetics}


The square symbols in Figures 5 and 6 represent the experimental variation of the cyt $\mathrm{c}$ concentration with time in the kinetic adsorption experiments performed with the OX and CX samples. The lines correspond to the best fittings to the LDSDM (left plots) and HSDM (right plots) equations. The logarithmic insets allow a better visualization of the data over the time scale. The values of the fitting parameters and errors are shown in Table 1. All the LDSDM fittings show significantly lower errors than the HSDM fittings. On average, the load-dependent surface diffusion model produces an error $2.6 \pm 1.1$ times lower than that produced by the homogeneous surface diffusion model. Furthermore, every HSDM fitting yields a different, and anomalously high, $\mathrm{k}_{\mathrm{S}}$ value. The external mass transfer coefficient depends on the size of the particles as well as on the hydrodynamics of the liquid (mainly shaking speed), and therefore it should be fairly similar for all the samples. The LDSDM fittings show lower errors with only one $\mathrm{k}_{\mathrm{S}}$ value for all the samples (Table 1), which, together with the surface diffusion coefficients, results in minimum values of the external mass transfer Biot number of between 93.1 and 138.7, in the regime of intraparticle diffusion control. As indicated in Table 1, the optimization process produced the best fitting results when $\mathrm{D}_{\mathrm{m}}=0$. With this value, equation (5) becomes:

$D_{S}(r, t)=D_{0}\left[1-\left(\frac{q(r, t)}{q_{m}}\right)^{m}\right]$

Equation (20) confirms that the diffusion of cyt $\mathrm{c}$ inside the xerogels is hindered by previously adsorbed biomolecules, as pointed out elsewhere [46, 58]. The values of $\mathrm{D}_{0}$ and $\mathrm{m}$ for each material are indicated in Table 1. Additionally, Figure 7 makes it easier to appreciate this negative effect, the extent of which clearly depends on the mean pore diameter of the materials. A load-averaged surface diffusion coefficient can be evaluated for each material by means of the following expression:

$$
\left\langle D_{S}\right\rangle=\frac{1}{q_{m}} \int_{0}^{q_{m}} D_{S}(r, t) d q=D_{0}\left(\frac{m}{m+1}\right)
$$


It is worth pointing out that the values of $\left\langle\mathrm{D}_{\mathrm{S}}\right\rangle$ obtained with this equation for all samples are around 3 times larger than the corresponding surface diffusivity values obtained by applying the HSDM (Table 1).

Table 1 and Figure 7 show that the CX and OX samples with pores larger than $15 \mathrm{~nm}$ have similar diffusion coefficients $\left(D_{0}\right.$ values in the $8.5 \times 10^{-8}-9.7 \times 10^{-8} \mathrm{~cm}^{2} \mathrm{~s}^{-1}$ range and $\left\langle\mathrm{D}_{\mathrm{S}}\right\rangle$ values in the $3.3 \times 10^{-8}-4.1 \times 10^{-8} \mathrm{~cm}^{2} \mathrm{~s}^{-1}$ range), and that there is an almost linear decrease in $D_{\mathrm{S}}$ with the load. However, OX-15, in spite of having a $\mathrm{D}_{0}$ value similar to that of the OX and CX samples with larger pore diameters, shows a steeper decrease in $\mathrm{D}_{\mathrm{S}}$ with load (Fig.7A) and, consequently, a much lower mean diffusion coefficient $\left(\left\langle\mathrm{D}_{\mathrm{S}}\right\rangle=1.8 \times 10^{-8} \mathrm{~cm}^{2} \mathrm{~s}^{-1}\right)$. It is clear that pore diameters close to the molecular size of the adsorbate entail pore wall effects that greatly affect the variation of the surface diffusion coefficient with the load. Even the zero-load value of the surface diffusion coefficient $\left(\mathrm{D}_{0}\right)$ seems to be affected by the mean pore diameter when this is sufficiently low, as observed in the case of CX-15 $\left(\mathrm{D}_{0}=6.5 \times 10^{-8} v s \sim 9 \times 10^{-8} \mathrm{~cm}^{2} \mathrm{~s}^{-1}\right.$ for CX-30 and CX-55). OX-15 however does not suffer from this effect and shows a $D_{0}$ value similar to that of OX-30 and OX-55 $\left(\sim 9 \times 10^{-8} \mathrm{~cm}^{2} \mathrm{~s}^{-1}\right)$. In spite of the differences in surface chemistry of the OX and CX materials, this is most likely due to the fact that the mean pore diameter of $\mathrm{OX}-15$ is greater than that of $\mathrm{CX}-15$, as can be seen in the pore size distribution plots in Figure 8, which were obtained by applying the 2D-NLDFT model [50] to the $\mathrm{N}_{2}$ physisorption isotherms shown in the same figure. It seems that a pore diameter of $15 \mathrm{~nm}$ (or a ratio of molecular size to pore diameter of $\lambda=0.27$ ), as determined by mercury intrusion, is the frontier below which (or above which, in the case of $\lambda$ ) the effect of the opposite wall pore on the diffusion the cyt $\mathrm{c}$ molecules begins to be noticeable even at a very low load.

To study the applicability of the LDSD model under different operation conditions, kinetic adsorption experiments were performed on CX-30 samples by varying operation parameters, such as the initial concentration of cyt c (Fig. 9A), the adsorbent dosage (Fig. 9B) and the agitation speed (Fig. 9C). To fit the experimental data to the model, all fitting parameters previously obtained for 
CX-30 and shown in Table 1 (equilibrium isotherm parameters, surface diffusion coefficients and external mass transfer coefficient) were kept unchanged in the calculations, except for the data obtained from the experiment performed at a low agitation speed (75 r.p.m.; Fig. 9C), where the $\mathrm{k}_{\mathrm{s}}$ parameter was allowed to vary during the fitting process, resulting in an optimum $\mathrm{k}_{\mathrm{S}}$ value of $3 \times 10^{-4} \mathrm{~cm} \mathrm{~s}^{-1}$. As can be seen in Figure 9, all fitting curves reproduce to a reasonable degree the experimental data plots, confirming the validity of the LDSD model under different operation conditions. The use of different agitation speeds did not produce any significant change in the experimental kinetic curves over 75 r.p.m. ( $\left(\mathrm{Bi}_{\mathrm{m}}\right.$ values for the fitting curves over $\sim 60$ ), as might have been expected from the plots included in Figure 1B. Lower agitation speeds could not be tested due to particle segregation.

Assuming a bulk diffusivity for cyt $\mathrm{c}$ of $1.1 \times 10^{-6} \mathrm{~cm}^{2} \mathrm{~s}^{-1}$ [58] and a molecular size of $\sim 4 \mathrm{~nm}$, the theoretical (non-surface) diffusion coefficient in the pores can be evaluated by applying the Higdon and Muldowney equation [59, 60]. Figure 10 compares the theoretical pore diffusion coefficients with the experimental surface diffusion coefficients obtained by the LDSDM fittings for the CX samples. The surface diffusion coefficients at zero load $\left(\mathrm{D}_{0}\right)$ are 4-8 times lower than the theoretical pore diffusivities, and these differences increase substantially if the mean surface diffusion coefficient $\left(\left\langle\mathrm{D}_{\mathrm{S}}\right\rangle\right)$ is taken into account. Its value, in the most extreme case of CX-15, is 28 times lower than that of the theoretical pore diffusivity. This is additional proof of the expediency of employing a surface diffusion model when dealing with cyt $\mathrm{c}$ adsorption onto mesoporous materials, as already discussed by Pandey et al. [58].

\section{Conclusions}

In this work, the adsorption of cytochrome $\mathrm{c}$ onto organic and carbon xerogels was observed to follow a quasi-Langmuirian pattern of behavior, as a result of which a monolayer of cyt $\mathrm{c}$ with a 
depth of $\sim 4 \mathrm{~nm}$ was formed on the surface of all xerogels. The minimum packing density of the protein inside the pores was found to be $0.23 \mathrm{~g} \mathrm{~cm}^{-3}$, although the value necessary for the formation of the monolayer is $0.29 \mathrm{~g} \mathrm{~cm}^{-3}$. A load-dependent surface diffusion model (LDSDM) was developed and numerically solved to fit the experimental kinetic adsorption curves. The results of the LDSDM show that fewer errors occur in the curve fittings than with the standard homogeneous surface diffusion model. The value of the external mass transfer Biot number obtained by the LDSDM confirms that the process is controlled by the intraparticle surface diffusion of cyt $\mathrm{c}$. The surface diffusion coefficients decrease with increasing load to zero for the maximum attainable load. The decrease is steeper for the xerogels with the smallest mean pore diameter $(\sim 15 \mathrm{~nm})$, the limit at which the zero-load diffusion coefficient of cyt $\mathrm{c}$ begins to be negatively affected by interaction between the protein and the opposite pore wall.

\section{Acknowledgements}

The financial support for this research work provided by the Spanish MINECO (CTM2014-56770-R project) and FEDER Funds (GRUPIN14-102 and GRUPIN14-117, Principado de Asturias) is gratefully acknowledged. LARM thanks CONACYT (México) for the award of a post-doctoral grant (CVU No 330625, 2016). We thank Dr. J.B. Parra for his suggestions relating the discussion about the pore size distributions of the materials.

\section{Reference list}

[1] H. Qiu, L. Lv, B.-c. Pan, Q.-j. Zhang, W.-m. Zhang, Q.-x. Zhang, J. Zhejiang Univ. Sci. A 10 (2009) 716-724.

[2] S. Lagergren, Handlingar 24 (1898) 1-39.

[3] Y.-S. Ho, Journal of Hazardous Materials 136 (2006) 681-689.

[4] M. Mahramanlioglu, I. Kizilcikli, I.O. Bicer, Journal of Fluorine Chemistry 115 (2002) 41-47.

[5] C.W. Cheung, J.F. Porter, G. McKay, Water Research 35 (2001) 605-612.

[6] M.J.D. Low, Chemical Reviews 60 (1960) 267-312.

[7] G.E. Boyd, A.W. Adamson, L.S. Myers, Journal of the American Chemical Society 69 (1947) 2836-2848. 
[8] W.J. Weber, J.C. Morris, Journal of the Sanitary Engineering Division, American Society of Civil Engineering 89 (1963) 31-60.

[9] M. Alkan, Ö. Demirbaş, M. Doğan, Microporous and Mesoporous Materials 101 (2007) 388396.

[10] A. Wilczak, T.M. Keinath, Water Environment Research 65 (1993) 238-244.

[11] S. Azizian, Journal of Colloid and Interface Science 276 (2004) 47-52.

[12] Y. Liu, L. Shen, Langmuir 24 (2008) 11625-11630.

[13] A.W. Marczewski, Langmuir 26 (2010) 15229-15238.

[14] F.B. Scheufele, A.N. Módenes, C.E. Borba, C. Ribeiro, F.R. Espinoza-Quiñones, R.

Bergamasco, N.C. Pereira, Chemical Engineering Journal 284 (2016) 1328-1341.

[15] H.S. Juneja, A. Iqbal, J. Yao, F. Shadman, Industrial \& Engineering Chemistry Research 45 (2006) 6585-6593.

[16] I.A. Vinokurov, J. Kankare, Langmuir 18 (2002) 6789-6795.

[17] I. Karasová, Czech J Phys 39 (1989) 1378-1391.

[18] K. Grabowski, A. Patrykiejew, S. Sokolowski, Thin Solid Films 352 (1999) 259-268.

[19] I. Langmuir, Physical Review 8 (1916) 149-176.

[20] I. Langmuir, Journal of the American Chemical Society 40 (1918) 1361-1403.

[21] S. Brunauer, P.H. Emmett, E. Teller, Journal of the American Chemical Society 60 (1938) 309319.

[22] G. Marbán, Journal of Colloid and Interface Science (2016).

[23] H. Spahn, E.U. Schlünder, Chemical Engineering Science 30 (1975) 529-537.

[24] A. Mathews, J. Weber, J. Walter, AIChE symposium series 73 (1977) 91-98.

[25] C.Y. Um, J.S. Mang, M.G. Kang, K.B. Ko, Chemical Engineering Communications DOI: 10.1080/00986445.2015.1118626 (2015).

[26] M.S. El-Geundi, Adsorption Science \& Technology 8 (1991) 217-225.

[27] C.H. Liaw, J.S.P. Wang, R.A. Greenkorn, K.C. Chao, AIChE Journal 25 (1979) 376-381.

[28] H. Pedersen, L. Furler, K. Venkatasubramanian, J. Prenosil, E. Stuker, Biotechnology and Bioengineering 27 (1985) 961-971.

[29] H. Yoshida, M. Yoshikawa, T. Kataoka, AIChE Journal 40 (1994) 2034-2044.

[30] G.L. Skidmore, B.J. Hortsmann, H.A. Chase, Journal of Chromatography A 498 (1990) 113128.

[31] A.E. Ivanov, O.P. Kozynchenko, L.I. Mikhalovska, S.R. Tennison, H. Jungvid, V.M. Gun'ko, S.V. Mikhalovsky, Physical Chemistry Chemical Physics 14 (2012) 16267-16278.

[32] L.-C. Sang, M.-O. Coppens, Physical Chemistry Chemical Physics 13 (2011) 6689-6698.

[33] R.D. Tilton, C.R. Robertson, A.P. Gast, Journal of Colloid and Interface Science 137 (1990)

192-203.

[34] L.E. Weaver, G. Carta, Biotechnology Progress 12 (1996) 342-355.

[35] P.R. Wright, F.J. Muzzio, B.J. Glasser, Biotechnology Progress 14 (1998) 913-921.

[36] M. Maekawa, K. Kasai, M. Nango, Colloids and Surfaces A: Physicochemical and Engineering Aspects 132 (1998) 173-179.

[37] Z. Ma, R.D. Whitley, N.H.L. Wang, AIChE Journal 42 (1996) 1244-1262.

[38] W.-D. Chen, X.-Y. Dong, Y. Sun, Journal of Chromatography A 962 (2002) 29-40.

[39] A. Kapoor, R.T. Yang, Chemical Engineering Science 45 (1990) 3261-3270.

[40] K. Higashi, H. Ito, J. Oishi, Nippon Genshiryoku Gakkaishi (Japan) 5 (1963).

[41] Y.D. Chen, R.T. Yang, AIChE Journal 37 (1991) 1579-1582.

[42] Y. Chen, R.T. Yang, Carbon 36 (1998) 1525-1537.

[43] V.P. Zhdanov, Surface Science 195 (1988) L217-L221.

[44] N. Rey-Raap, J. Angel Menéndez, A. Arenillas, Microporous and Mesoporous Materials 195 (2014) 266-275.

[45] N. Rey-Raap, J. Angel Menéndez, A. Arenillas, Carbon 78 (2014) 490-499. 
[46] L.A. Ramírez-Montoya, A. Concheso, I.D. Alonso-Buenaposada, H. García, J. Angel Menéndez, A. Arenillas, M.A. Montes-Morán, Carbon 118 (2017) 743-751.

[47] O. Redlich, D.L. Peterson, The Journal of Physical Chemistry 63 (1959) 1024-1024.

[48] S.G. Poulopoulos, V.J. Inglezakis, Adsorption, ion exchange and catalysis: design of operations and environmental applications, Elsevier, 2006.

[49] G.-h. Xiu, L. Jiang, P. Li, Industrial \& Engineering Chemistry Research 39 (2000) 4054-4062. [50] J. Jagiello, C. Ania, J.B. Parra, C. Cook, Carbon 91 (2015) 330-337.

[51] N. Job, R. Pirard, J. Marien, J.-P. Pirard, Carbon 42 (2004) 619-628.

[52] I.D. Alonso-Buenaposada, N. Rey-Raap, E.G. Calvo, J.A. Menéndez, A. Arenillas, Journal of Sol-Gel Science and Technology DOI 10.1007/s10971-017-4475-z (2017).

[53] R.E. Dickerson, T. Takano, D. Eisenberg, O.B. Kallai, L. Samson, A. Cooper, E. Margoliash, Journal of Biological Chemistry 246 (1971) 1511-1535.

[54] G.P. Gorbenko, Biochimica et Biophysica Acta (BBA) - Biomembranes 1420 (1999) 1-13.

[55] G.W. Bushnell, G.V. Louie, G.D. Brayer, Journal of molecular biology 214 (1990) 585-595.

[56] I.D. Alonso-Buenaposada, A. Arenillas, M.A. Montes-Morán, J.A. Menéndez, Journal of NonCrystalline Solids 471 (2017) 202-208.

[57] M. Haghgoo, A.A. Yousefi, M.J.Z. Mehr, A.F. Léonard, M.P. Philippe, P. Compère, A. Léonard, N. Job, Journal of materials science 50 (2015) 6007-6020.

[58] B. Pandey, K.H. Tran Ba, Y. Li, R. Diaz, T. Ito, Electrochimica Acta 56 (2011) 10185-10190.

[59] J.J.L. Higdon, G.P. Muldowney, Journal of Fluid Mechanics 298 (2006) 193-210.

[60] S. Lu, Z. Song, J. He, The Journal of Physical Chemistry B 115 (2011) 7744-7750. 


\section{Captions to figures}

Figure 1. LDSDM simulation results for the varying operation conditions (when not otherwise stated $\mathrm{C}_{0}=0.5 \mathrm{mg} \mathrm{cm}{ }^{-3} ; \mathrm{D}_{\mathrm{A}}=0.002 \mathrm{~g} \mathrm{~cm}^{-3} ; \rho_{\mathrm{a}}=0.46 \mathrm{~g} \mathrm{~cm}^{-3} ; \mathrm{R}=0.05 \mathrm{~cm} ; \mathrm{k}_{\mathrm{S}}=1 \times 10^{-3} \mathrm{~cm} \mathrm{~s}^{-1} ; \mathrm{D}_{0}=1 \times 10^{-7} \mathrm{~cm}^{2} \mathrm{~s}^{-1} ;$ $\mathrm{D}_{\mathrm{m}}=0 \mathrm{~cm}^{2} \mathrm{~s}^{-1}$; m=1): A) particle size; B) $\mathrm{Bi}_{\mathrm{m}}$ (agitation speed); C) adsorbent dosage; D) initial adsorbate concentration and E) apparent density.

Figure 2. LDSDM simulation results for the varying surface diffusion coefficients (when not otherwise stated $C_{0}=0.5 \mathrm{mg} \mathrm{cm}^{-3} ; \mathrm{D}_{\mathrm{A}}=0.002 \mathrm{~g} \mathrm{~cm}^{-3} ; \rho_{\mathrm{a}}=0.46 \mathrm{~g} \mathrm{~cm}^{-3} ; \mathrm{R}=0.05 \mathrm{~cm} ; \mathrm{k}_{\mathrm{S}}=1 \times 10^{-3} \mathrm{~cm} \mathrm{~s}^{-1}$; $\left.\mathrm{D}_{0}=1 \times 10^{-7} \mathrm{~cm}^{2} \mathrm{~s}^{-1} ; \mathrm{D}_{\mathrm{m}}=0 \mathrm{~cm}^{2} \mathrm{~s}^{-1} ; \mathrm{m}=1\right)$ : A) $\mathrm{D}_{0}$ for $\mathrm{D}_{0}>\mathrm{D}_{\mathrm{m}}$; B) $\mathrm{m}$ for $\mathrm{D}_{0}>\mathrm{D}_{\mathrm{m}} ;$ C) $\mathrm{D}_{\mathrm{m}}$ for $\mathrm{D}_{0} \geq \mathrm{D}_{\mathrm{m}}$ $\left(\mathrm{D}_{0}=5 \times 10^{-9} \mathrm{~cm}^{2} \mathrm{~s}^{-1}\right)$ and $\left.\mathrm{D}\right) \mathrm{D}_{0}$ for $\mathrm{D}_{0} \leq \mathrm{D}_{\mathrm{m}}\left(\mathrm{D}_{\mathrm{m}}=5 \times 10^{-9} \mathrm{~cm}^{2} \mathrm{~s}^{-1}\right)$.

Figure 3. Equilibrium adsorption isotherms for the adsorption of cyt c onto OX samples. Solid lines represent fittings to the Redlich-Peterson equation (fitting parameters shown in Table 1).

Figure 4. Equilibrium adsorption isotherms for the adsorption of cyt c onto CX samples. Solid lines represent fittings to the Redlich-Peterson equation (fitting parameters shown in Table 1).

Figure 5. Variation of $\mathrm{C}_{\mathrm{b}}$ with time for the different organic xerogels (operation conditions and fitting parameters indicated in Table 1). Solid lines: curve fittings to the load-dependent surface diffusion model (left plots) and to the homogeneous surface diffusion model (right plots). Insets: the same plots with a time axis on a logarithmic scale.

Figure 6. Variation of $\mathrm{C}_{\mathrm{b}}$ with time for the different carbon xerogels (operation conditions and fitting parameters indicated in Table 1). Solid lines: curve fittings to the load-dependent surface diffusion model (left plots) and to the homogeneous surface diffusion model (right plots). Insets: the same plots with a time axis on a logarithmic scale.

Figure 7. Variation of the surface diffusion coefficient with load obtained by applying the LDSDM to the adsorption of cyt c onto: A) the organic xerogels and B) the carbon xerogels. 
Figure 8. $\mathrm{N}_{2}$ adsorption isotherms and 2D-NLDFT pore size distributions for OX-15 and CX-15.

Figure 9. Variation of $\mathrm{C}_{\mathrm{b}}$ with time for CX-30 under varying operation conditions: A) different initial concentrations of cyt $\mathrm{c}\left(\mathrm{D}_{\mathrm{A}}=0.002 \mathrm{~g} \mathrm{~cm}^{-3}, 200\right.$ r.p.m.); B) different adsorbent dosages $\left(\mathrm{C}_{0}=0.5 \mathrm{~g} \mathrm{~cm}^{-3} ; 200\right.$ r.p.m. $)$ and C) different agitation speeds $\left(\mathrm{C}_{0}=0.5 \mathrm{mg} \mathrm{cm}^{-3} ; \mathrm{D}_{\mathrm{A}}=0.002 \mathrm{~g} \mathrm{~cm}^{-3}\right)$. Solid lines: curve fittings to the load-dependent surface diffusion model with the $\mathrm{k}_{\mathrm{s}}, \mathrm{D}_{0}$ and $\mathrm{D}_{\mathrm{m}}$ parameters indicated in Table 1 for CX-30 (except for the plot at 75 r.p.m. in Fig. C, for which $\mathrm{k}_{\mathrm{s}}=3 \times 10^{-4} \mathrm{~cm} \mathrm{~s}^{-1}$ ). Insets: the same plots with a time axis on a logarithmic scale

Figure 10. Variation of theoretical (non-surface) pore diffusivity $[59,60]$ and experimental surface diffusion coefficients $\left(\mathrm{D}_{0}\right.$ and $\left.\left\langle\mathrm{D}_{\mathrm{S}}\right\rangle\right)$ with mean pore diameter, evaluated for the $\mathrm{CX}$ samples. 


\section{Tables}

Table 1. Textural properties and parameters of the equilibrium adsorption isotherms and models of adsorption kinetics for the different $\mathrm{OX}$ and $\mathrm{CX}$ samples

\begin{tabular}{|c|c|c|c|c|c|c|}
\hline Samples & OX-15 & OX-30 & OX-55 & CX-15 & CX-30 & CX-55 \\
\hline \multicolumn{7}{|l|}{ Characterization } \\
\hline$\left\langle\mathrm{d}_{\mathrm{p}}>(\mathrm{nm})^{\mathrm{a}}\right.$ & - & - & - & 15 & 30 & 55 \\
\hline$V_{p}\left(\mathrm{~cm}^{3} \mathrm{~g}^{-1}\right)^{a}$ & $0.99^{\mathrm{b}}$ & $1.21^{\mathrm{b}}$ & $1.53^{\mathrm{b}}$ & 0.88 & 1.32 & 1.48 \\
\hline $\mathrm{V}_{\mu}\left(\mathrm{cm}^{3} \mathrm{~g}^{-1}\right)^{\mathrm{c}}$ & 0.13 & 0.09 & 0.05 & 0.26 & 0.24 & 0.24 \\
\hline $\mathrm{S}_{\mathrm{BET}}\left(\mathrm{m}^{2} \mathrm{~g}^{-1}\right)^{\mathrm{c}}$ & 308 & 236 & 137 & 679 & 625 & 640 \\
\hline$\rho_{\mathrm{a}}\left(\mathrm{cm}^{3} \mathrm{~g}^{-1}\right)$ & 0.55 & 0.49 & 0.42 & 0.61 & 0.46 & 0.43 \\
\hline \multicolumn{7}{|c|}{ Equilibrium isotherm (Redlich-Peterson) } \\
\hline $\mathrm{A}$ & 186459.0 & 65899.8 & 76551.1 & 115911.3 & 111654.0 & 163741.1 \\
\hline $\mathrm{B}$ & 771.4 & 350.8 & 504.6 & 524.0 & 658.1 & 1364.8 \\
\hline g & 0.9528 & 0.9811 & 0.9550 & 0.8319 & 0.9770 & 0.9702 \\
\hline $\mathrm{q}_{\mathrm{m}}\left(\mathrm{mg} \mathrm{g}^{-1}\right)^{\mathrm{d}}$ & 235.5 & 185.2 & 147.8 & 202.4 & 167.3 & 118.0 \\
\hline $\mathrm{X}_{\mathrm{V}}^{\mathrm{e}}$ & - & - & - & 0.79 & 0.44 & 0.27 \\
\hline $\mathrm{D}(\mathrm{nm})^{\mathrm{e}}$ & - & - & - & 4.1 & 3.7 & 4.1 \\
\hline \multicolumn{7}{|c|}{ Kinetics HSDM $^{\mathrm{f}}\left(\mathrm{C}_{0}=0.5 \mathrm{mg} \mathrm{cm}^{-3} ; \mathrm{D}_{\mathrm{A}}=0.002 \mathrm{~g} \mathrm{~cm}^{-3}\right)$} \\
\hline $\mathrm{k}_{\mathrm{S}}\left(\mathrm{cm} \mathrm{s}^{-1}\right)$ & 3.33 & 1.91 & 0.60 & 1.98 & 1.30 & 3.57 \\
\hline $\mathrm{D}_{\mathrm{S}}\left(\mathrm{cm}^{2} \mathrm{~s}^{-1}\right)$ & $5.60 \times 10^{-9}$ & $1.07 \times 10^{-8}$ & $1.32 \times 10^{-8}$ & $3.59 \times 10^{-9}$ & $1.16 \times 10^{-8}$ & $1.49 \times 10^{-8}$ \\
\hline Error, $\varepsilon$ & $1.12 \times 10^{-2}$ & $6.62 \times 10^{-3}$ & $4.53 \times 10^{-3}$ & $3.18 \times 10^{-3}$ & $5.17 \times 10^{-3}$ & $1.05 \times 10^{-3}$ \\
\hline \multicolumn{7}{|c|}{ Kinetics LDSDM ${ }^{\mathrm{g}}\left(\mathrm{C}_{0}=0.5 \mathrm{mg} \mathrm{cm}^{-3} ; \mathrm{D}_{\mathrm{A}}=0.002 \mathrm{~g} \mathrm{~cm}^{-3}\right)$} \\
\hline $\mathrm{k}_{\mathrm{S}}\left(\mathrm{cm} \mathrm{s}^{-1}\right)$ & \multicolumn{6}{|c|}{$5.40 \times 10^{-4}$} \\
\hline $\mathrm{D}_{\mathrm{m}}\left(\mathrm{cm}^{2} \mathrm{~s}^{-1}\right)$ & \multicolumn{6}{|c|}{0} \\
\hline $\mathrm{q}_{\mathrm{e}}\left(\mathrm{mg} \mathrm{g}^{-1}\right)^{\mathrm{h}}$ & 212.3 & 178.5 & 140.3 & 165.4 & 161.5 & 114.8 \\
\hline $\mathrm{Bi}_{\mathrm{m}}^{\mathrm{i}}$ & 104.2 & 103.6 & 99.4 & 138.7 & 105.4 & 93.1 \\
\hline $\mathrm{D}_{0}\left(\mathrm{~cm}^{2} \mathrm{~s}^{-1}\right)$ & $8.64 \times 10^{-8}$ & $8.69 \times 10^{-8}$ & $9.05 \times 10^{-8}$ & $6.49 \times 10^{-8}$ & $8.54 \times 10^{-8}$ & $9.66 \times 10^{-8}$ \\
\hline $\mathrm{m}$ & 0.27 & 0.61 & 0.68 & 0.17 & 0.64 & 0.72 \\
\hline$\left.<\mathrm{D}_{\mathrm{S}}\right\rangle\left(\mathrm{cm}^{2} \mathrm{~s}^{-1}\right)$ & $1.83 \times 10^{-8}$ & $3.29 \times 10^{-8}$ & $3.66 \times 10^{-8}$ & $9.62 \times 10^{-9}$ & $3.33 \times 10^{-8}$ & $4.06 \times 10^{-8}$ \\
\hline Error, E & $5.66 \times 10^{-3}$ & $1.96 \times 10^{-3}$ & $1.63 \times 10^{-3}$ & $2.59 \times 10^{-3}$ & $1.20 \times 10^{-3}$ & $5.87 \times 10^{-4}$ \\
\hline
\end{tabular}

${ }^{\mathrm{a}} \mathrm{Hg}$ intrusion $\left(\mathrm{d}_{\mathrm{p}}>3.5 \mathrm{~nm}\right) ;{ }^{\mathrm{b}}$ Affected by the sample compressibility; ${ }^{\mathrm{c}} \mathrm{N}_{2}$ physisorption; ${ }^{\mathrm{d}}$ Load at equilibrium for $\mathrm{C}_{\mathrm{e}}=0.6 \mathrm{mg} \mathrm{cm}^{-3}$; ${ }^{\mathrm{e}}$ For a cyt c packing density of $0.29 \mathrm{~g} \mathrm{~cm}^{-3}$ (see discussion); ${ }^{\mathrm{f}}$ Equation (2); ${ }^{\mathrm{g}}$ Equation (6); ${ }^{\mathrm{h}}$ Load at equilibrium for $\mathrm{C}_{0}=0.5 \mathrm{mg} \mathrm{cm}{ }^{-3} ;{ }^{\mathrm{i}}$ At zero load 


\section{Figures}
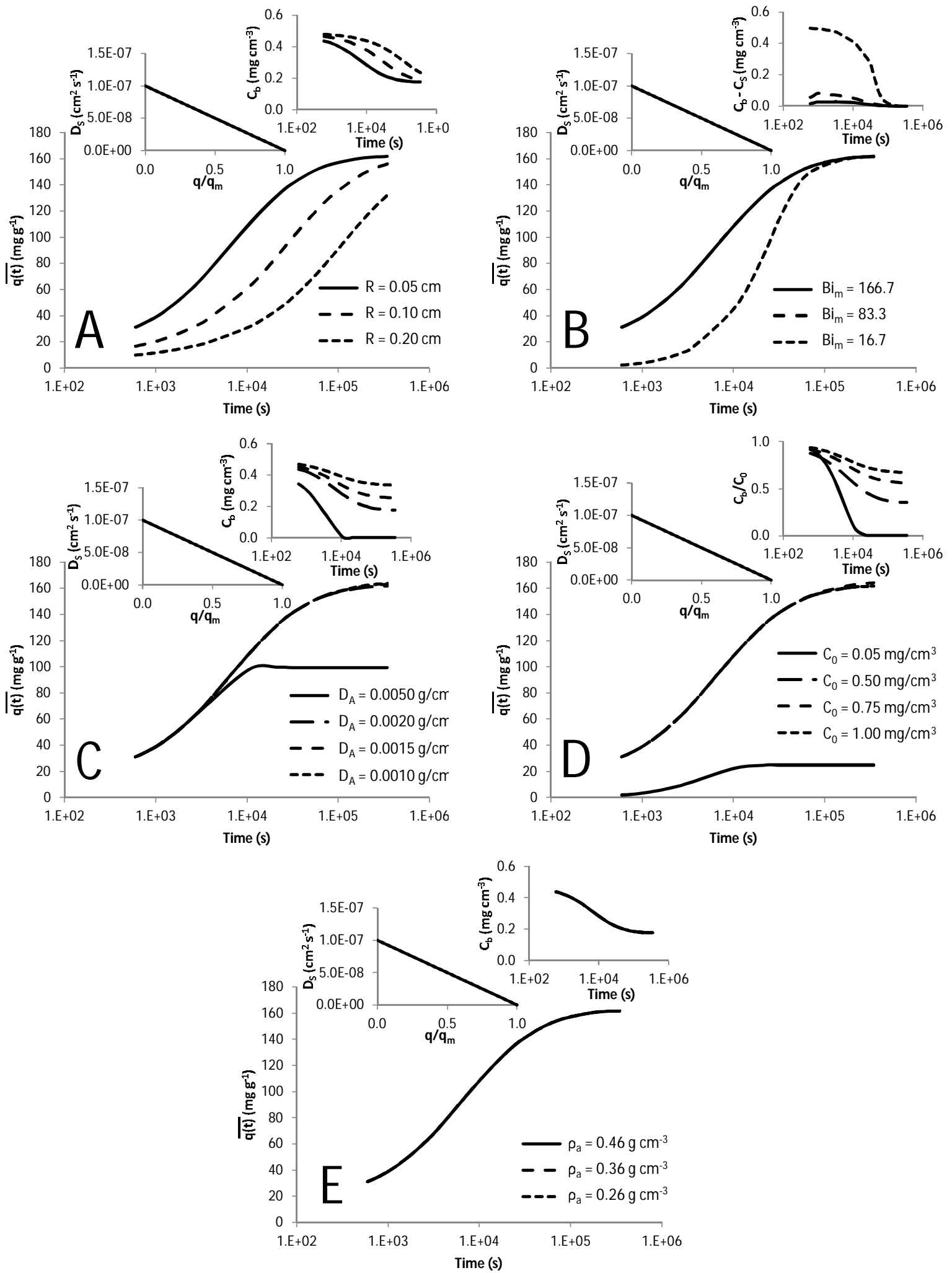

Figure 1 

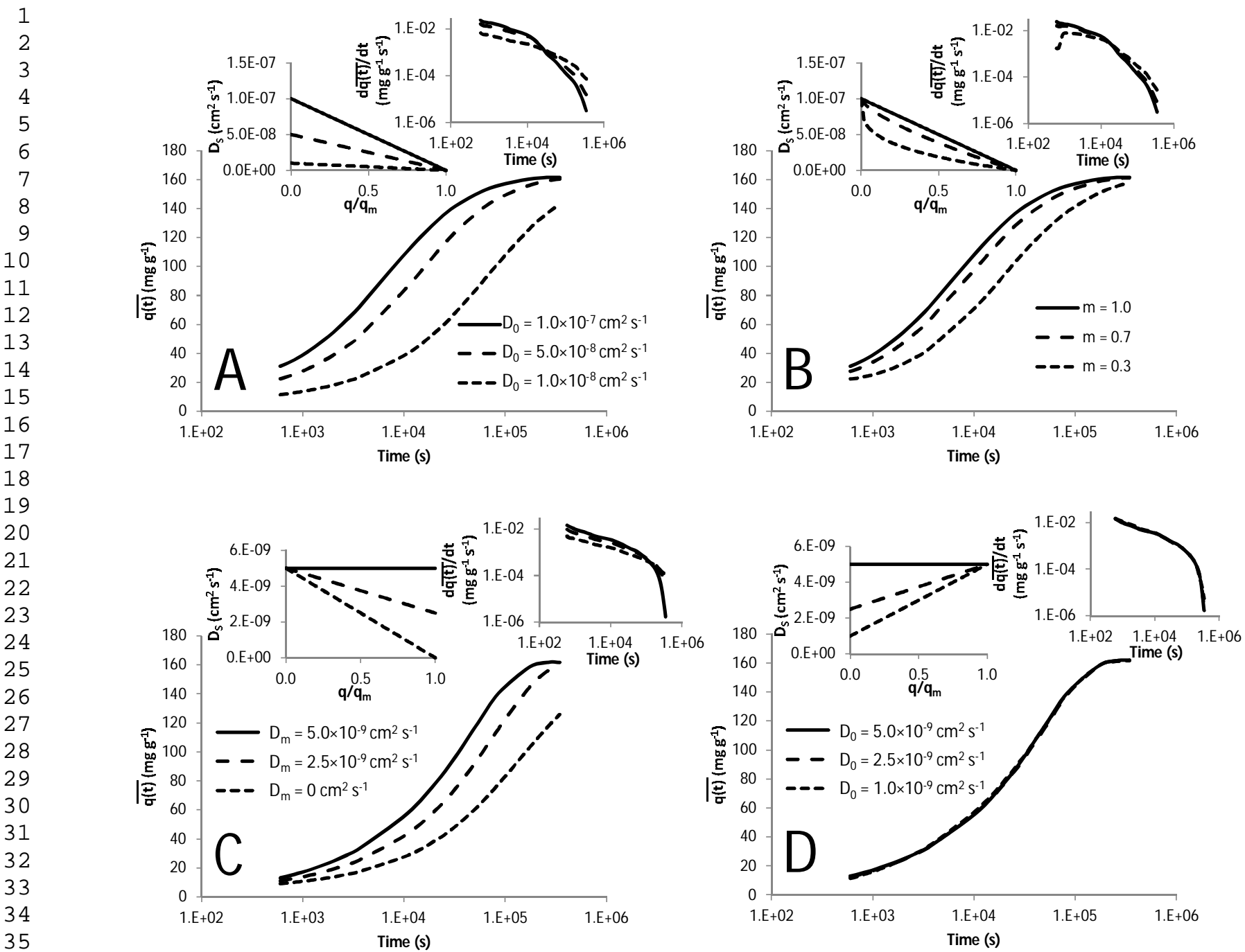

Figure 2 


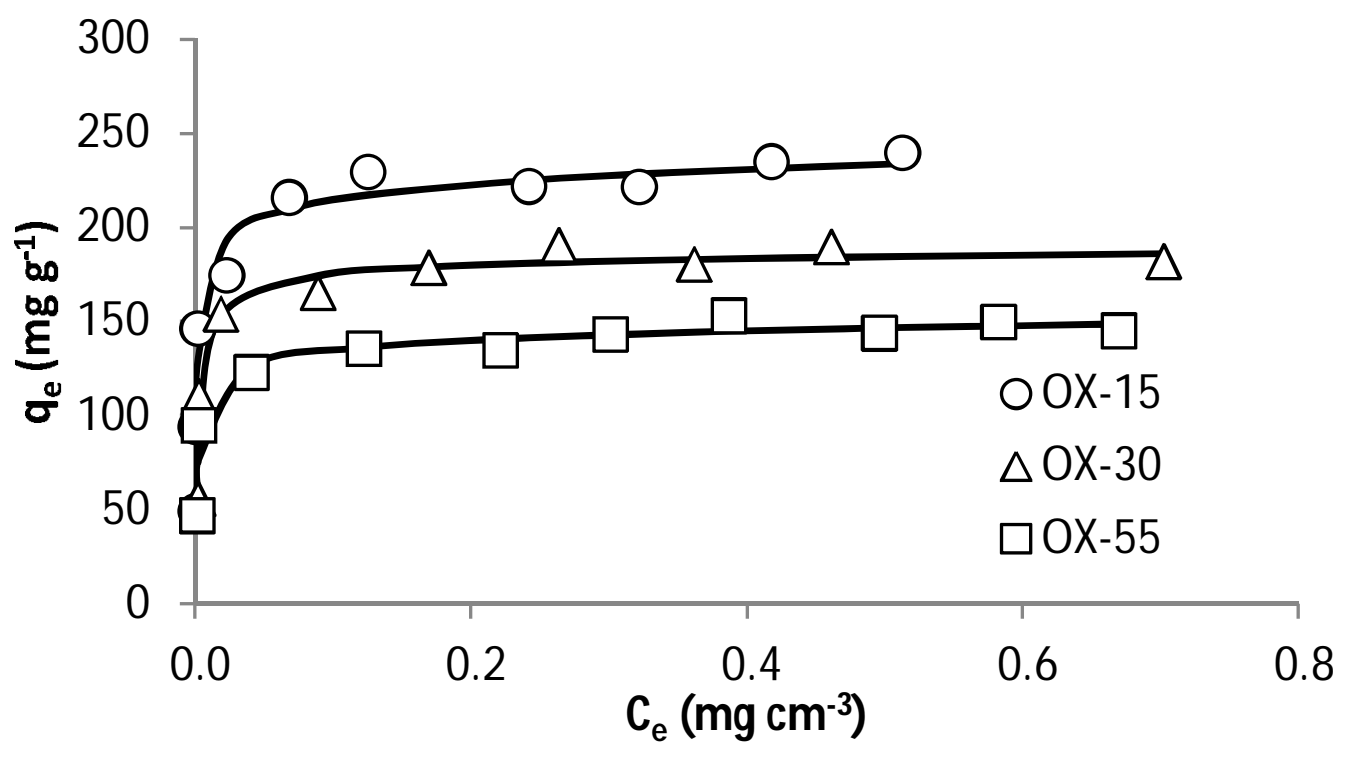

Figure 3 


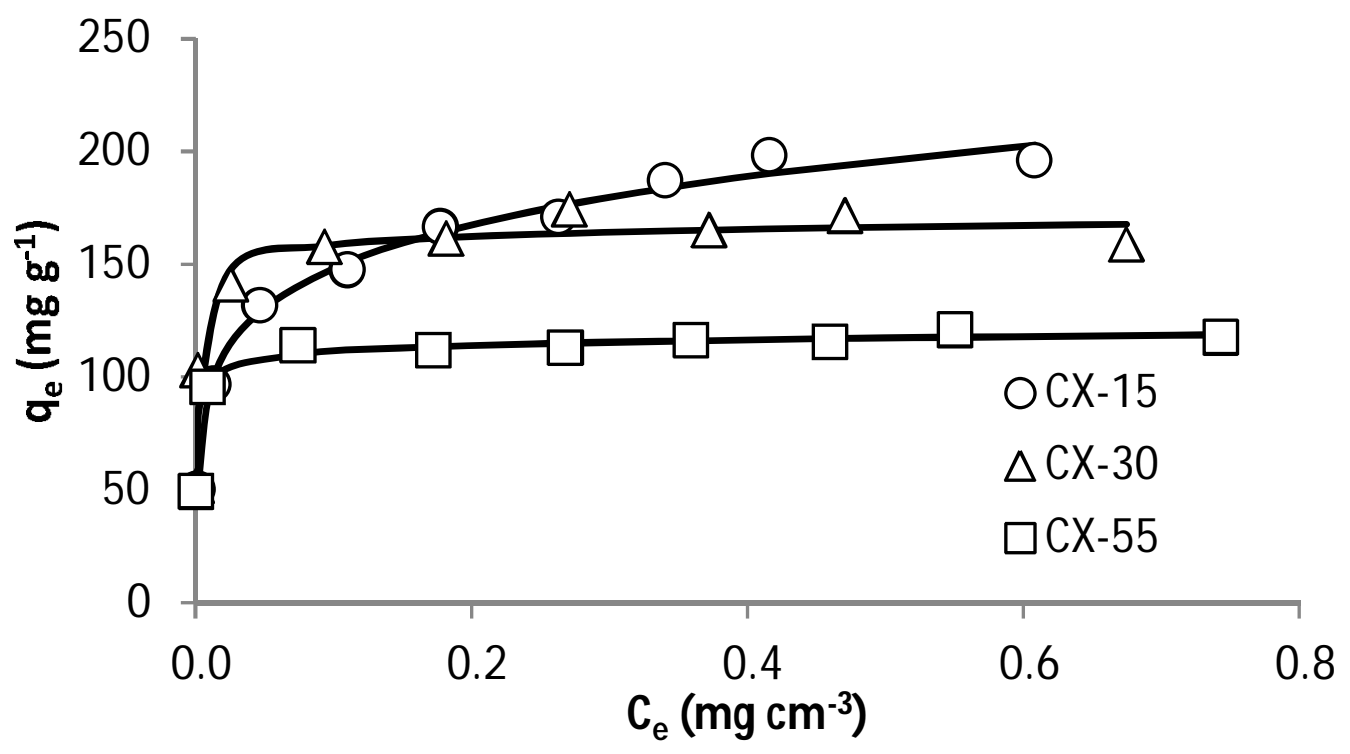

Figure 4 

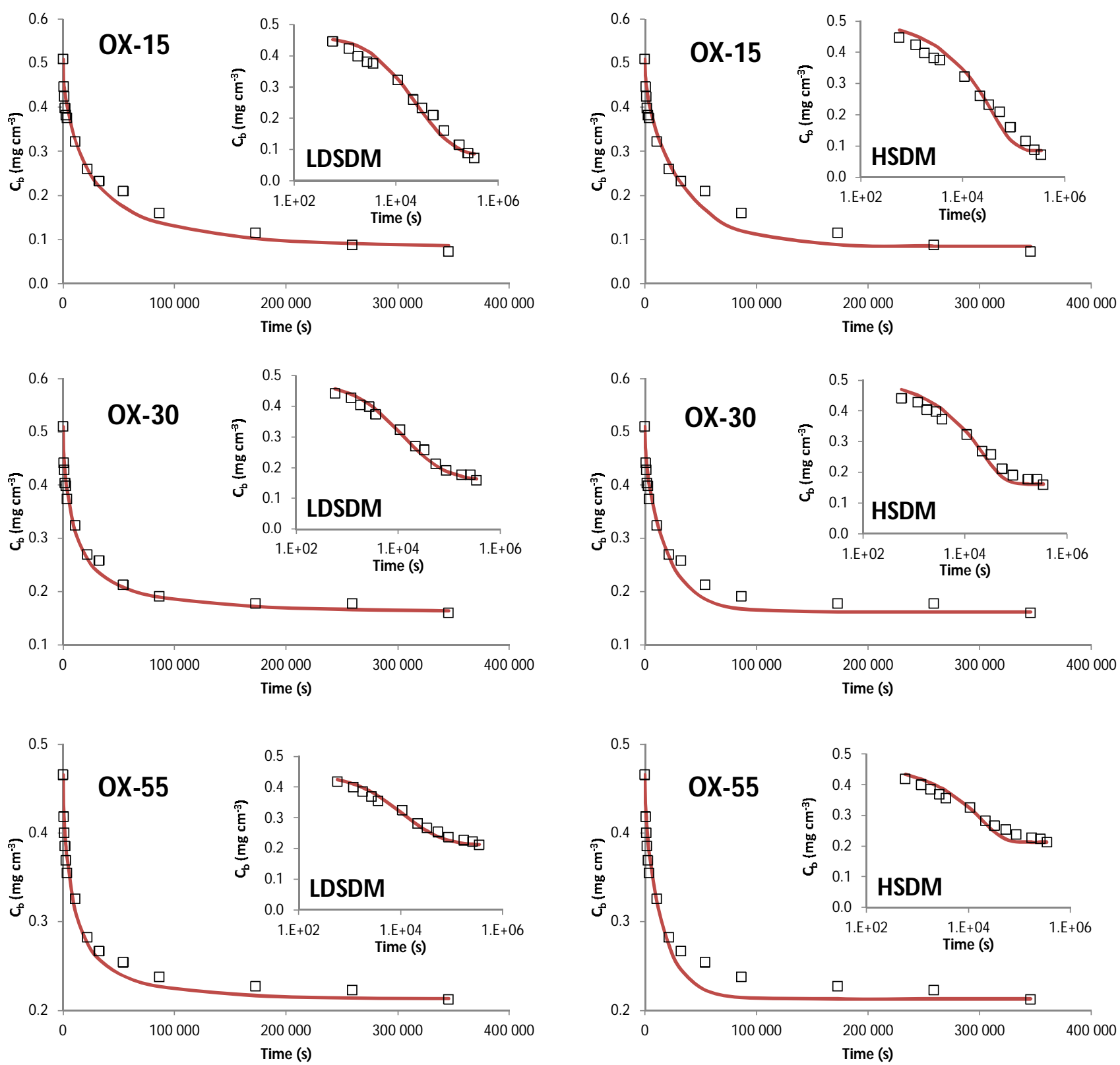

Figure 5 

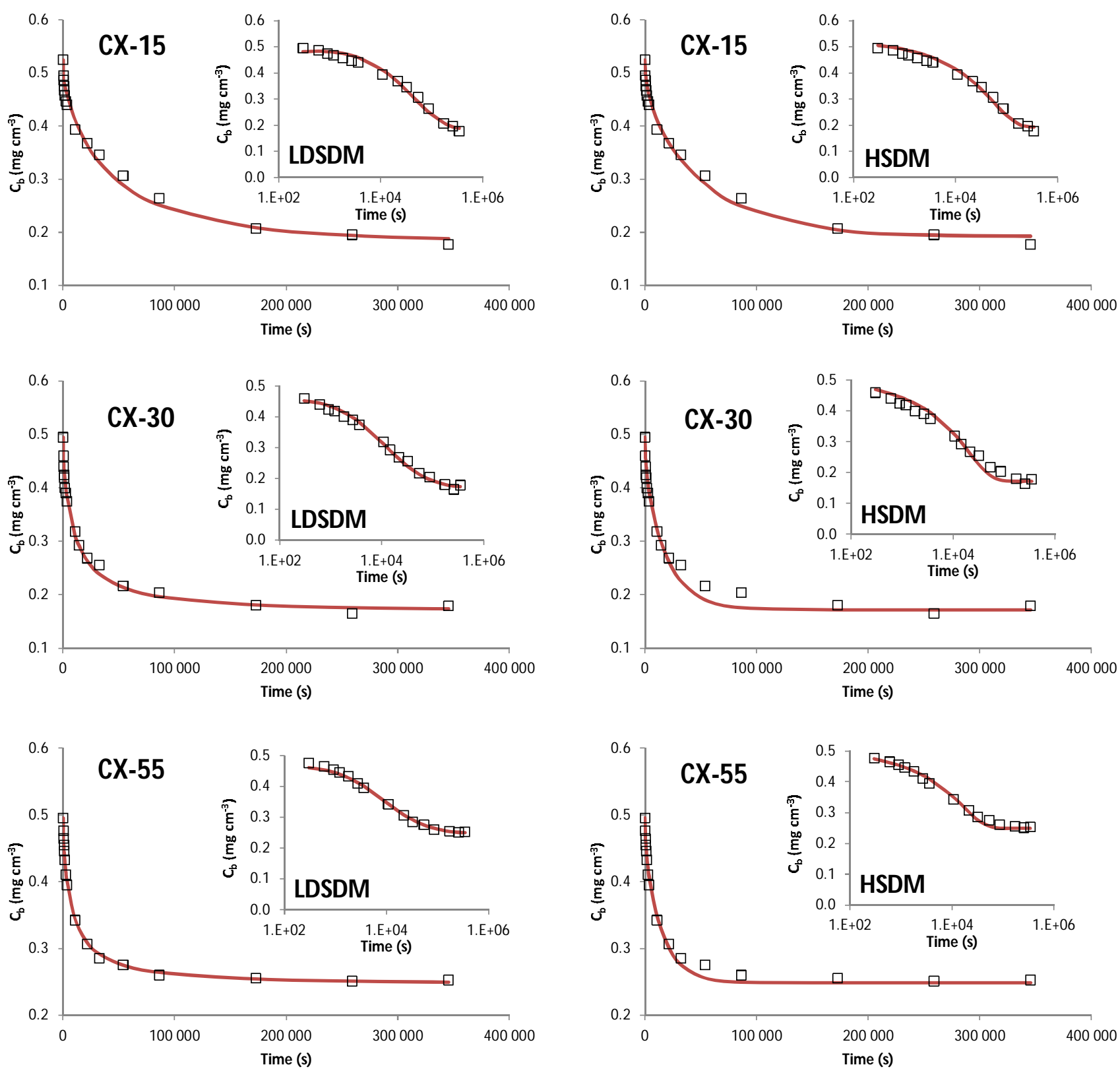

Figure 6 

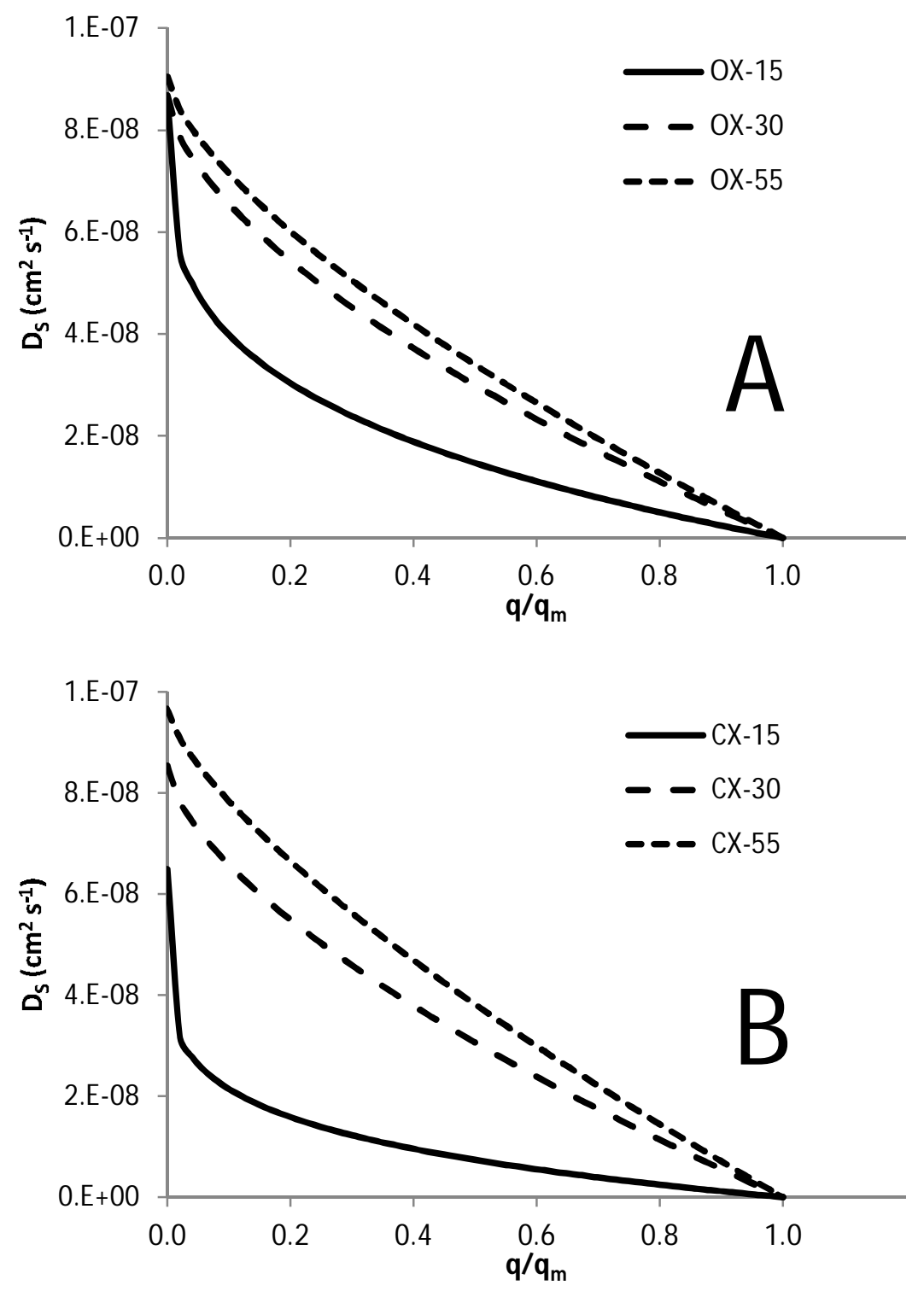

Figure 7 


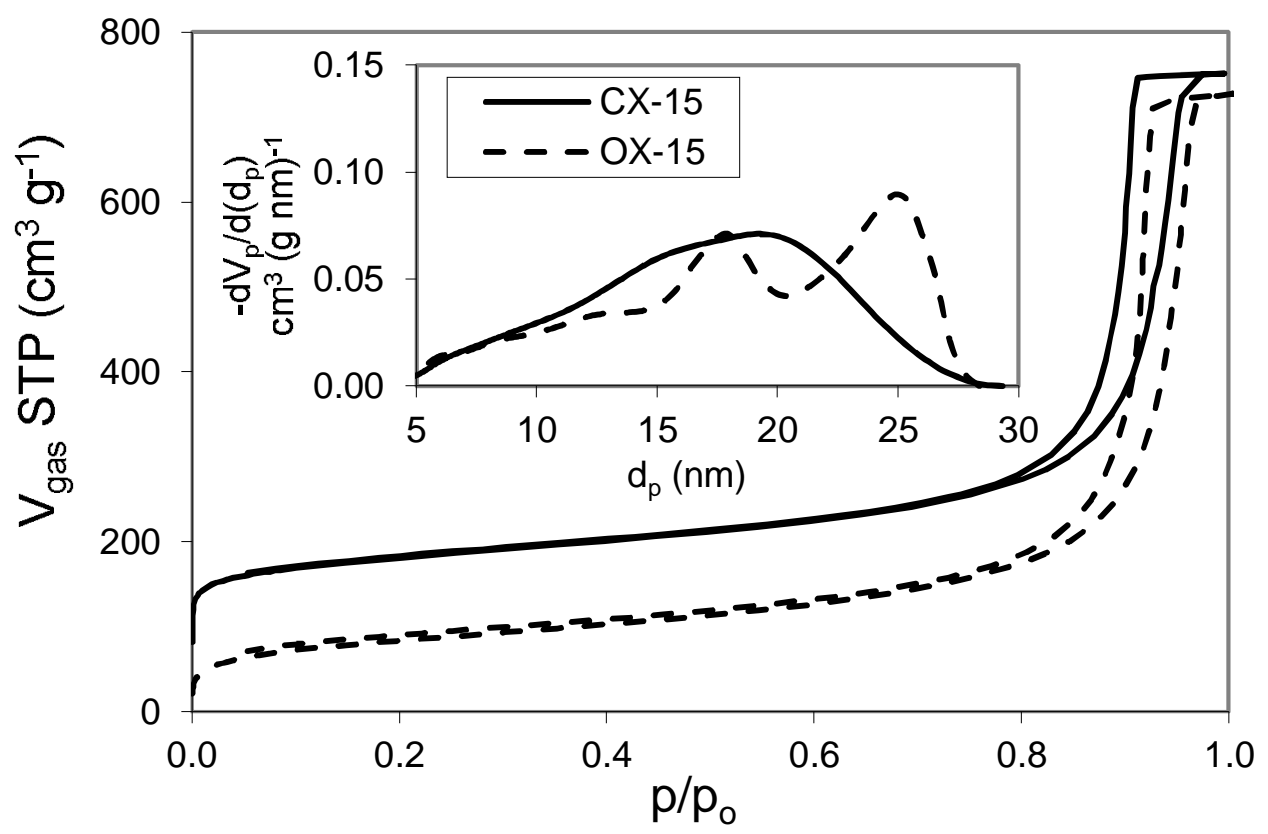

Figure 8 



Figure 9 


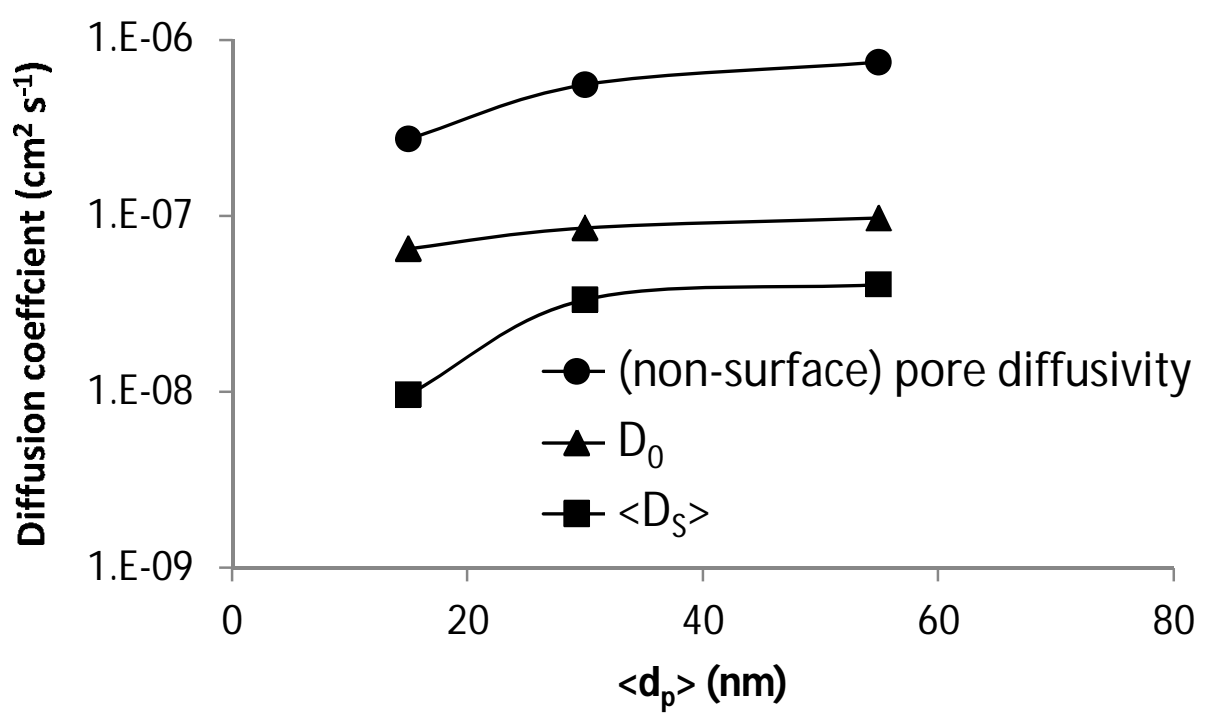

Figure 10 